\title{
ТЕОРЕТИЧЕСКИЕ АСПЕКТЫ АВТОМАТИЗАЦИИ ПРОЦЕССОВ УЧЕТА ВЕЩЕВОГО ИМУЩЕСТВА В СИСТЕМЕ ТЫЛОВОГО ОБЕСПЕЧЕНИЯ ВОЙСК НАЦИОНАЛЬНОЙ ГВАРДИИ РОССИЙСКОЙ ФЕДЕРАЦИИ 1
}

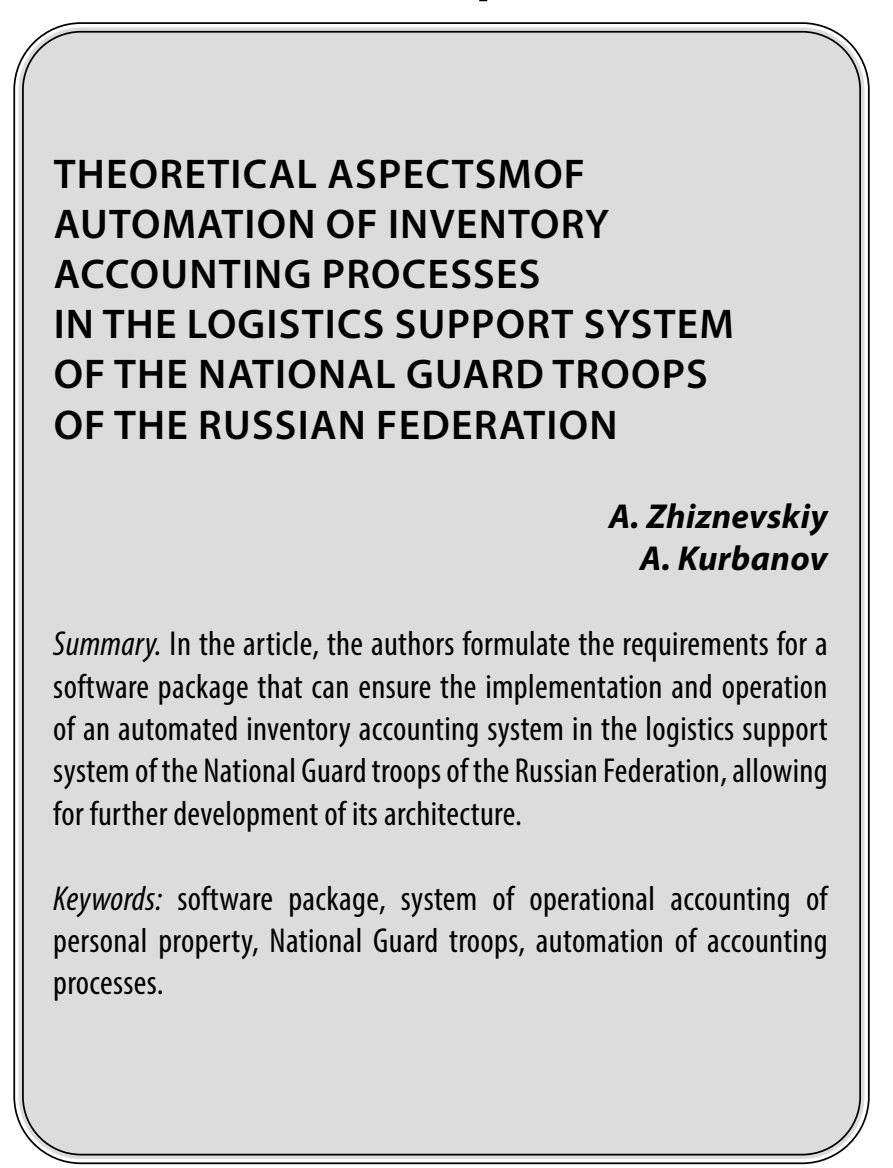

B рамках реализации национальной программы Цифровая экономика Российской Федерации», утвержденной президиумом Совета при Президенте Российской Федерации по стратегическому развитию и национальным проектам 4 июня 2019 г. [1], в войсках национальной гвардии продолжается работа по совершенствованию ведомственной системы учета материальных средств и автоматизации отдельных ее подсистем с формированием отдельных аналитических подсистем.

В ходе проработки возможности автоматизации процессов учета вещевого имущества структурными подразделениями центрального аппарата Росгвардии

\author{
Жизневский Анатолий Николаевич \\ Федеральная служба войск национальной гвардии \\ Российской Федерации \\ ana-1338_1982@mail.ru \\ Курбанов Артур Хусаинович \\ Д.э.н., профессор, Военная академия материально- \\ технического обеспечения имени генерала армии \\ A.В. Хрулёва \\ kurbanov-83@yandex.ru
}

Аннотация. В работе авторы формулируют требования к программному комплексу, способному обеспечить внедрение и функционирование системы автоматизированного учета вещевого имущества в системе тылового обеспечения войск национальной гвардии Российской Федерации, позволяющие в дальнейшем разработать его архитектуру.

Ключевые слова: программный комплекс, система оперативного учета вещевого имущества, войска национальной гвардии, автоматизация процессов учета. одним из основных проблемных вопросов, препятствующих внедрению передовых технологий, является отсутствие программного обеспечения, способного обеспечить обработку и систематизацию поступающей при считывании информации радиочастотных меток или штрих-кодов о количестве и качественных характеристиках материальных средств.

При определении требований к указанному программному обеспечению приоритетным направлением автоматизации процессов определен материальный учет с возможностью интеграции в ведомственную систему бухгалтерского учета. 


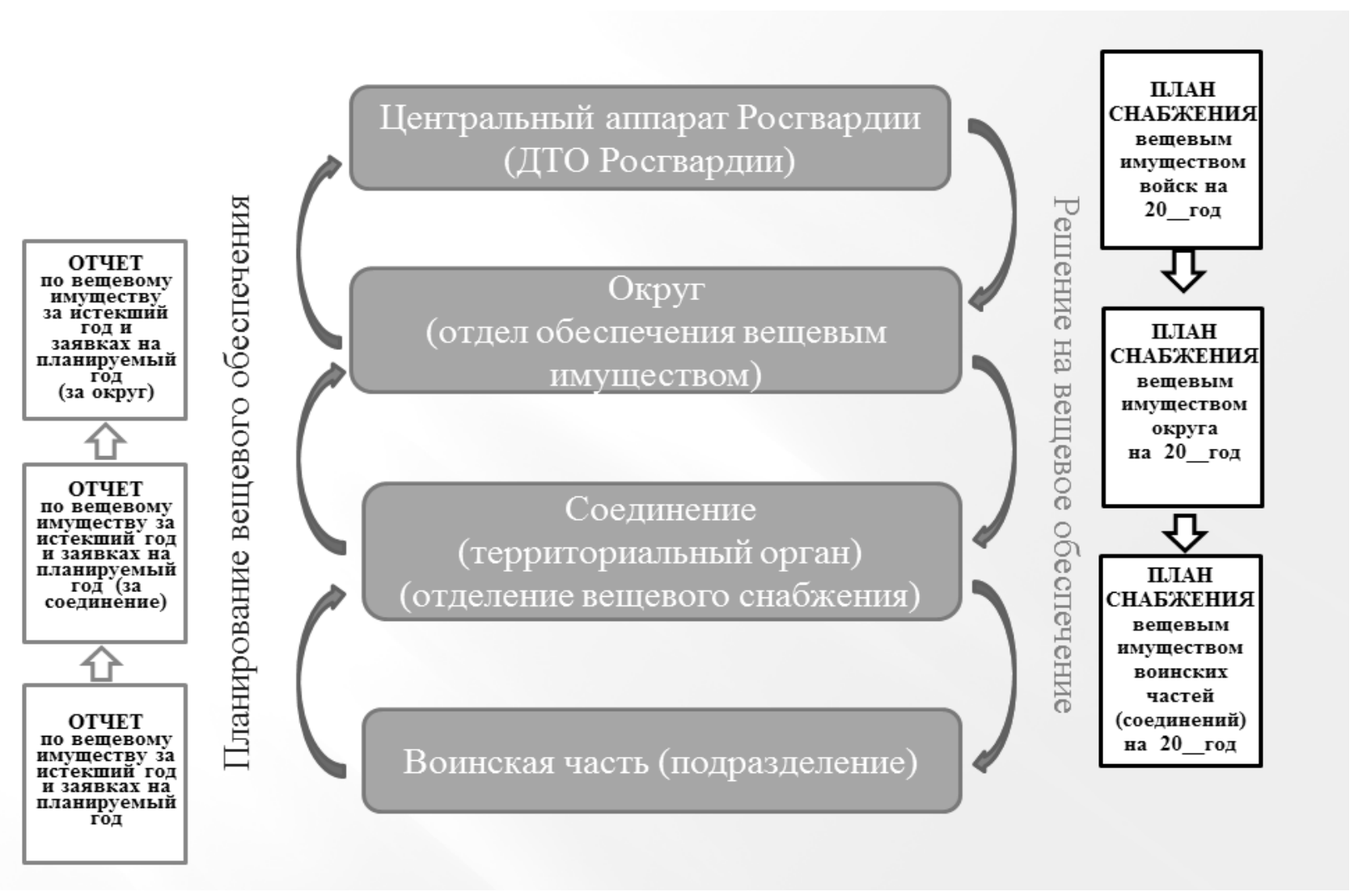

Рис. 1. Порядок (последовательность) планирования и принятия решений на вещевое обеспечение в войсках национальной гвардии Российской Федерации

1. Цель разработки программного комплекса - автоматизация процессов учета движения имущества и технических средств вещевой службы (далее - вещевое имущество) и отчетности по вещевому обеспечению.

2. Задачи разработки программного комплекса:

- формирование системы оперативного учета вещевого имущества, позволяющей органам управления вещевым обеспечением войск оперативно принимать решения на дообеспечение с учетом наличия вещевого имущества на складах и обеспеченности воинских частей (подразделений) в любой момент времени [3];

- автоматизация процесса расчета потребности воинских частей (подразделений) в вещевом имуществе;

- автоматизация процессов учета движения вещевого имущества в количественных показателях;

- автоматизация процессов начисления положенности вещевого имущества военнослужащим (сотрудникам) и подразделениям войск;

- автоматизация процессов составления отчетности (планирования) по вещевому обеспечению.

\section{3. Замысел на разработку программного комплекса.}

3.1. Программный комплекс должен обеспечивать автоматизацию процессов учета движения вещевого имущества в воинской части (подразделении), планирования вещевого обеспечения (снизу - вверх: от воинской части (подразделения) до Департамента тылового обеспечения Федеральной службы войск национальной гвардии Российской Федерации 1) и принятия решений на вещевое обеспечение (сверху - внизу: от ДТО Росгвардии до воинской части (подразделения).

Формирование остатков и расчет потребности (положенности) осуществляется в воинской части (подразделении) на основании данных учета о фактическом наличии вещевого имущества на складе и в подразделениях, совершенных приходно-расходных операциях, а также состояния обеспеченности военнослужащих (сотрудников) и подразделений (см. рис. 1).

Отчетные документы о фактическом наличии вещевого имущества на складах и обеспеченности воинской

\footnotetext{
Далее - «ДТО Росгвардии».
} 




Рис. 2. Автоматизация процессов учета вещевого имущества с применением программного комплекса.

части (подразделения) формируются в автоматизированном режиме и передаются в вышестоящие органы управления вещевым обеспечением без возможности внесения в них изменений.

3.2. Учет движения вещевого имущества в воинской части (подразделении) организуется и ведется начальником вещевой службы или другим должностным лицом, ответственным за вещевое обеспечение, по отношению к объектам хранения и эксплуатации вещевого имущества (складам, банно-прачечным комплексам, вещевым ремонтным мастерским и подразделениям).

Процессы учета движения вещевого имущества в воинской части (подразделении), подлежащие автоматизации, включают в себя:

- учет операций склада вещевого имущества по поступлению и выдаче вещевого имущества, формирование остатков вещевого имущества в количественных показателях по наименованиям, маркам, размерам (ростам и полнотам), ар- тикулам, остатку срока эксплуатации (для предметов инвентарного имущества), учет свободных мест хранения;

- учет фактического наличия вещевого имущества, находящегося в эксплуатации подразделений, в количественных показателях по наименованиям (маркам) с учетом проведенных приходно-расходных операций;

- учет состояния обеспеченности и начисления положенности вещевого имущества военнослужащим, проходящим военную службу по контракту, (сотрудникам);

- начисление денежной компенсации взамен неполученных предметов вещевого имущества военнослужащим, проходящим военную службу по контракту (сотрудникам);

- сверки с финансовым органом воинской части (подразделения);

- передача отчетов об остатках вещевого имущества на складах и в подразделениях воинской части (подразделения) в вышестоящий орган вещевого обеспечения. 
3.3. В отделах хранения ЦМТО Росгвардии автоматизации подлежит учет операций склада по поступлению и выдаче вещевого имущества воинским частям (подразделениям), формирование остатков вещевого имущества в количественных показателях по наименованиям, маркам, размерам (ростам и полнотам), артикулам.

3.4. В соединениях автоматизации подлежит процесс формирования сводных остатков вещевого имущества на складах подчиненных воинских частей (подразделений) и сведений об их обеспеченности вещевым имуществом, а также процесс передачи указанных сведений в вышестоящий орган управления вещевым обеспечением (отдел вещевого обеспечения округа).

3.5. В округах автоматизации подлежит процесс формирования сводных остатков вещевого имущества на складах подчиненных соединений и воинских частей (подразделений), сведений об их обеспеченности вещевым имуществом, а также процесс передачи указанных сведений в вышестоящий орган управления вещевым обеспечением (ДТО Росгвардии).

\section{6. В ДТО Росгвардии автоматизации подлежит про-} цесс формирования сводных остатков вещевого имущества на складах подчиненных округов, соединений и воинских частей (подразделений), сведений об их обеспеченности вещевым имуществом (рис. 2).

4. Объекты автоматизации - процессы учета вещевого имущества текущего обеспечения.

5. Сведения об информации, подлежащей обработке - количественные показатели о поступающем на склады воинской части (подразделения) или отдела хранения вещевого имущества, выдаваемом в воинские части (подразделения) вещевом имуществе, и фактическом наличии вещевого имущества на складах (в подразделениях), состоянии обеспеченности воинских частей (подразделений) и военнослужащих, проходящих военную службу по контракту (сотрудников), вещевым имуществом, не составляющие государственную тайну.

5. Режим работы программного комплекса - постоянный.

6. Требования к программному комплексу:

- простота использования;

- точность формируемых сведений;

- использование передовых технологий (способов) учета (радиочастотная идентификация и штрих-кодирование);
- оперативность передачи сведений потребителям (до 1 часа);

- возможность интеграции с программным обеспечением «1С-бухгалтерия» в вопросах проведения сверок о наличии вещевого имущества в подразделениях и на складах, начисления положенности и подтверждения выдачи вещевого имущества подразделениям и военнослужащим (сотрудникам);

- работа во внутренней информационной сети Росгвардии и предоставление доступа исключительному кругу должностных лиц;

- возможность формирования документов начальника вещевой службы (арматурной карточки, справки на выплату денежной компенсации взамен неполученного вещевого имущества, раздаточных ведомостей на выдачу вещевого имущества военнослужащим, проходящим военную службу по контракту (сотрудникам), отчета по вещевому имуществу за прошедший год и заявки на планируемый год), их автоматической отправки в финансовый орган на исполнение;

- исключение возможности изменения формируемых данных учета и отчетности без подтверждения совершения приходно-расходной операции по объекту учета.

Таким образом, разработка программного комплекса с учетом изложенных требований предполагает формирование аналитической подсистемы автоматизированной системы учета материальных средств, способной удовлетворить потребности органов управления вещевым обеспечением на всех уровнях построения войск национальной гвардии в достоверной и оперативной информации о состоянии обеспеченности подчиненных соединения (воинских частей) и территориальных органов (подразделений) вещевым имуществом, их фактической потребности в нем, что позволит повысить эффективность принимаемых решений на тыловое обеспечений войск и обеспечить совершенствование действующей системы автоматизированного учета на основе программного обеспечения «1С-бухгалтерия» [2].

Результатом проводимой работы должно стать создание в войсках национальной гвардии системы оперативного учета вещевого имущества [3], архитектура которой может быть применена для учета иных видов материальных средств, поступающих на снабжение. Это создаст условия для успешного решения практических задач, возникающих в процессе обеспечения подразделений материальными средствами как в повседневной жизнедеятельности, так и при выполнении служебно-боевых (служебных) задач $[4,5]$. 


\section{ЛИТЕРАТУРА}

1. Паспорт национального проекта «Национальная программа «Цифровая экономика Российской Федерации», утверждена президиумом Совета при Президенте Российской Федерации по стратегическому развитию и национальным проектам, протокол от 4 июня 2019 г. № 7. URL: https://digital.gov.ru

2. Жизневский А.Н., Курбанов А.Х. Организация автоматизированного учета вещевого имущества в войсках национальной гвардии с применением контрольных идентификационных знаков [Текст] // Вестник Марийского государственного университета. Серия «Сельскохозяйственные науки. Экономические науки» Том 4, № 3, 2018. — С. 91-97.

3. Жизневский А.Н. Практический опыт работы вещевой службы воинской части по подготовке подразделений к действиям в составе группировки войск по охране общественного порядка и обеспечению общественной безопасности при проведении крупных международных мероприятий (на примере XXII зимних олимпийских игр) [Текст]// Сборник статей III международной научно-практической конференции «Тенденции развития МТ0 военной организации государства в современных условиях, ПВИ ВНГ России. - 2017 г.- С. 244-250.

4. Жизневский А.Н. Методические рекомендации по повышению эффективности тылового обеспечения воинских частей войск национальной гвардии при выполнении служебно-боевых задач в военном конфликте [Текст] // Научный сборник по обмену опытом обучения и воспитания ВАМТ0.2018. — № 56 .

5. Жизневский А.Н., Подопригора А.В. Возможности применения контрольных идентификационных знаков как путь совершенствования системы учета и отчетности вещевого имущества // Сборник докладов научно-практической конференции по итогам управленческой практики (войсковой стажировки) слушателей II курса академии, ВАМТ0.— 2018. - Ч. 1.- С. 63-67.

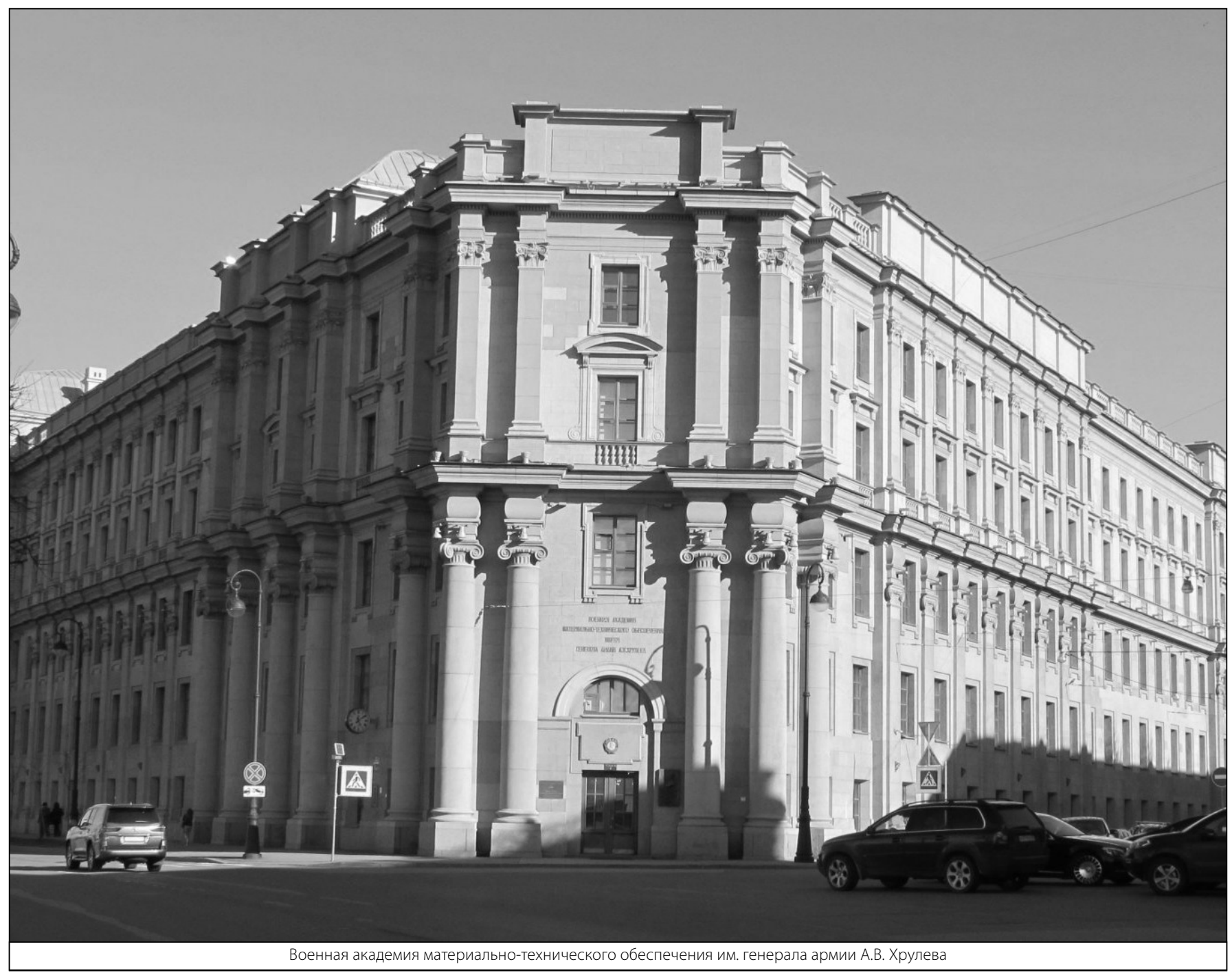

